J. Lake Sci. (湖泊科学), 2012, 24(1): 104-110

http: //www.jlakes.org. E-mail: jlakes@niglas. ac.cn

(c) 2012 by Journal of Lake Sciences

\title{
太湖鱼类放流增殖的有效数量和合理结构"
}

\author{
何 俊 $^{1,2}$, 谷孝鸿 $^{1 * *}$, 王小林 ${ }^{3}$, 吴林坤 $^{3}$, 陈非洲 ${ }^{1}$, 曹 萍 $^{3}$, 刘家驹 $^{4}$, 张宪中 $^{2}$ \\ (1: 中国科学院南京地理与湖泊研究所湖泊与环境国家重点实验室,南京 210008) \\ ( 2 : 江苏省无锡市水产技术推广站,无锡 214023) \\ (3: 江苏省太湖渔业管理委员会办公室,苏州 215004) \\ (4:金陵科技学院,南京 211169)
}

\begin{abstract}
摘 要: 根据 2006-2007 年太湖生物资源调查, 估算出太湖浮游植物、浮游动物、底栖动物和水生植物总渔产潜力约为 $78494 \mathrm{t}$. 太湖实施以渔改水的生物调控措施, 应加大鲢、鳙放流数量和放流规格, 在提高鱼产量的同时对抑制太湖蓝藻水 华能起到积极作用; 推算每年放流鲜约 $1000 \times 10^{4}$ 尾,鲢约 $300 \times 10^{4}$ 尾,规格为 20 尾 $/ \mathrm{kg}$ 为宜. 草鱼、团头鲂、青鱼、鲤等要 在保护太湖水草和底栖动物资源和生物多样性前提下适当放流, 每年宜放流草鱼 $150 \times 10^{4}$ 尾, 团头鲂 $165 \times 10^{4}$ 尾, 青鱼 $8 \times 10^{4} \sim 10 \times 10^{4}$ 尾, 鲤夏花 $2500 \times 10^{4}$ 尾. 而对调控鱼类结构小型化、单一化具有重要作用的肉食性鱼类趐嘴鲌建议加大 放流量, 年放流量可扩大至 $500 \times 10^{4}$ 尾左右, 在调控的同时提高湖泊渔业附加值.
\end{abstract}

关键词: 太湖;鱼类放流; 渔业结构;增殖

\section{Fish stocking quantities and structures of the fishery resources enhancement in Lake Taihu}

HE Jun ${ }^{1,2}$, GU Xiaohong ${ }^{1}$, WANG Xiaolin ${ }^{3}$, WU Linkun ${ }^{3}$, CHEN Feizhou ${ }^{1}$, CAO Ping ${ }^{3}$, LIU Jiaju ${ }^{4}$ \& ZHANG Xianzhong ${ }^{2}$

(1: State Key Laboratory of Lake Science and Environment, Nanjing Institute of Geography and Limnology, Chinese Academy of Sciences, Nanjing 210008, P. R. China)

(2: Aquaculture Technology Extension Station of Wuxi, Wuxi 214023, P. R. China)

(3: Lake Taihu Fishery Management Commission of Jiangsu Pvovince, Suzhou 215004, P. R. China )

(4: Jinling Institute of Technology, Nanjing 211169, P. R. China)

Abstract: According to the investigations of biological resources in Lake Taihu during 2006 - 2007 , we calculated that total fishery yield potential of phytoplankton, zooplankton, zoobenthos and aquatic macrophytes in Lake Taihu was about 78494 t. In order to increase fish yields and inhibit cyanobacteria bloom in Lake Taihu, stocking number of silver carp (Hypohthalmichthys molitrix Richardson) and bighead carp(Aristichthys nobilis Cuvier) should be increased to 10 million and 3 million tails, respectively, and the specification should be 20 tails per kilogram. To protect resources of aquatic macrophytes and zoobenthos, the reasonable stocking number of grass carp (Ctenopharyngodon idellus Cuvier), blunt snout bream ( Megalobrama amblycephala Yih), black carp (Mylopharyngodon piceus Richardson) and common carp(Cyprinidae carpio Linnaeus) should be 1. 5 million, 1.65 million, 80 100 thousand and 25 million tails, respectively. As topmouth cutler such as cutler alburnus could play important roles in controlling miniaturization and singleness of fishery structure and increase added-value of fishery economy, its stocking quantity should be increased to 5 million tails.

Keywords: Lake Taihu; fish stocking quantity; fishery structure; enhancement

* 国家重点基础研究发展计划“973” 项目(2008CB418104)、中国科学院知识创新工程重要方向性项目 (KSCX2-YWN-47) 和湖泊与环境国家重点实验室基金项目联合资助. 2011-01-30 收稿; 2011-04-15 收修改稿. 何俊, 女, 1982 年生, 硕士, 助理工程师; E-mail:wxhejun@ yahoo. cn.

** 通信作者;E-mail:xhgu@ niglas. ac. cn. 
太湖是我国第三大淡水湖,位于长江三角洲的长江南缘、江苏与浙江省交界处, 面积 $2338.1 \mathrm{~km}^{2}$, 平均水深 $2.12 \mathrm{~m}$, 换水周期为 $309 \mathrm{~d}$, 蓄水量 $49.6 \times 10^{8} \mathrm{~m}^{3}$, 是一个典型的碟型浅水湖泊 ${ }^{[1]}$. 渔业作为太湖重要生态功 能之一, 可划分为自然渔业与网围养殖渔业两大部分. 自然渔业以大湖区的捕捞渔业为主,网围养殖以东太 湖养殖河蟹为主. 当前太湖自然渔业的特点是: 自 1950s 起, 太湖渔业捕捞产量呈不断增长的趋势, 由 1952 年的 $4060 \mathrm{t}$ 增至 2006 年的 $35085 \mathrm{t}$. 但是目前的鱼类种群结构远不及 $1950 \mathrm{~s}$ 合理, 主要鱼类产量和组成以小 型低值鱼类梅鲚为优势, 产量比例高达 $60 \%$; 人工放流鱼类产量和在渔获物中比例仍偏低, 鲢鲔产量占 $7.4 \%$, 青草鱼占 $2.6 \%$, 鲤鲫鲂占 $9.4 \%$, 鲌占 $7.7 \%{ }^{[2]}$,增殖放流的放养结构与湖泊生态系统食物网结构配 置的密切性不够, 放流量不足随着太湖富营养化而加重, 生物饵料基础的增长使放流鱼类人工放流量仍有 较大提升空间,放流规格和品质也有待提高. 据此, 本文依托课题组 2006-2007 年太湖生物资源现状调查, 结合太湖历年鱼类放流和捕捞资料, 探讨太湖主要放流鱼类渔产潜力, 提出合理放流数量和放流规格; 同时 针对太湖捕捞渔获物中小型低值鱼占优势的情形, 试图通过研究肉食性鱼类渔产潜力以及合理放流数量, 运用食物链的营养级关系调控小型低值鱼类种群结构, 从而实现太湖渔业产量和结构的优化, 并达到通过 改变湖泊生态系统食物网结构改善太湖水环境的目的.

\section{1 材料与方法}

\section{1 太湖生物资源现状调查}

2006 年 10 月至 2007 年 11 月在太湖北湖区 (主要包括竺山湾、梅梁湾和贡湖湾)、大湖区 (太湖主体水 域)、东部沿岸区 (苏州附近水域) 和东太湖四个区域, 共设 14 个点, 进行浮游动物、浮游植物、底栖动物资源 调查. 于 2007 年 6 月 $10-18$ 日和 2007 年 10 月 16-19 日在太湖设 118 个采样点分别进行全太湖水生植物 夏秋季调查.

\section{2 太湖鱼类资源数据来源}

太湖 1993-2006 年鱼类放流和捕捞资料由江苏省太湖渔业管理委员会办公室提供; 太湖放流鱼类肥满 度数据源于课题组“2007 年太湖鱼类资源调查”.

\section{3 渔产潜力计算方法}

1.3.1 用能量法计算浮游植物渔产潜力 根据王䩀等 ${ }^{[3-4]}$ 提出的公式 $F_{\mathrm{Hy}}=F_{\mathrm{SC}} \times E_{\mathrm{Hy}} \times \mathrm{Hy} / \mathrm{C}, F_{\mathrm{Ar}}=F_{\mathrm{SC}} \times E_{\mathrm{Ar}}$ $\times \mathrm{Ar} / \mathrm{C}$ 计算浮游植物初级生产力. 其中, $F_{\mathrm{Hy}} 、 F_{\mathrm{Ar}}$ 分别为鲢和鲔的渔产潜力; $F_{\mathrm{SC}}$ 代表浮游植物对鲢鲬的供 饵能力, 为 $5.874 \times$ 湖区浮游植物年产量; $E_{\mathrm{H} y} 、 E_{\mathrm{Ar}}$ 分别为鲢鳙对浮游植物的能量转化率, 为 0.032 和 0.072 ; $\mathrm{Hy} 、 \mathrm{Ar}$ 是鲢鳙相对比例,分别为 0.7 和 $0.3 ; \mathrm{C}$ 为鲜鱼肉的热当量, 5.02 .

1.3.2 用 $\mathrm{P} / \mathrm{B}$ 系数法估算浮游动物、底栖动物和水生植物渔产潜力 根据公式 $F=m \times(P / B) \times a / K$ 计算渔 产潜力. 其中, $m$ 是覀料生物量; $P / B$ 是饵料生产量与现存量比值; $a$ 是饵料利用率; $K$ 是㱗料系数. 其中底栖 动物参照梁彦龄等的计算公式 ${ }^{[5]}$ : 软体动物为 $F_{\mathrm{M}}=0.032 \times B_{\mathrm{M}}$; 寊毛类为 $F_{0}=0.183 \times B_{0}$; 水生昆虫为 $F_{1}=0.235 \times B_{1}$.

\section{2 结果与分析}

\section{1 太湖水生生物资源现状}

此次调查共检测到浮游植物 8 门 104 属 193 种, 其中, 蓝藻门的微囊藻属在北湖区、大湖区和东部沿岸 区全年大部分时间数量上均占优势. 东太湖全年的组成变化与另三个湖区不同,微囊藻只在少数月份占优 势, 其它月份以隐藻、钟罩藻以及蓝藻、硅藻和绿藻的一些种类为主. 微囊藻生物量占浮游植物总生物量的 比值在北湖区、大湖区、东部沿岸区和东太湖分别为 $30.5 \% 、 47.4 \% 、 7.1 \%$ 和 $7.4 \%$.

浮游动物 104 属 162 种; 其中枝角类 33 种、桡足类 16 种、轮虫 63 种、原生动物只包括肉足纲和纤毛纲, 共 50 种, 种群组成中以小型浮游动物轮虫和原生动物为主. 底栖动物 51 属 57 种, 主要包括环节动物、软体 动物和水生昆虫. 北湖区全年以环节动物霍甫水丝蚓和中华河蚓占优势; 大湖区全年则以钩虾和河蚬占优 势; 东部沿岸区冬季以环节动物为主, 春季则以螺类为主; 东太湖全年以螺类为主.

调查采集到水生植物 11 种,按生态类型划分为: 沉水植物 (包括马来眼子菜、苦草、金鱼藻、轮叶黑藻、 
伊乐藻、茨藻和狐尾藻) 、浮叶植物 (包括荇菜、菱) 和挺水植物 (包括芦苇和菰). 其中主导植被类型是沉水 植物. 太湖的水生植物主要分布在东部各湖湾、西山和东山相连的湖区以及东太湖和南太湖相连的湖区. 另 外, 北部、西部和南部沿岸区有少量高等水生植被 (主要是芦苇) 分布.

\section{2 太湖水生生物生产力和渔产潜力}

太湖浮游植物初级生产力的最大潜能是 4-9 月的微囊藻群体, 太湖滤食浮游植物尤其是微囊藻的鱼 类主要是鲢和鳙. 浮游植物渔产潜力按照能量估算法, 根据浮游植物生物量, 以及太湖北湖区、大湖区、东部 沿岸区和东太湖面积 $\left(360 、 1592 、 213\right.$ 和 $\left.173 \mathrm{~km}^{2}\right)$ 和平均水深 $(1.9 、 1.9 、 1.8$ 和 $1.0 \mathrm{~m})$, 计算各湖区鲢鰎 的渔产潜力分别为 $1235.30 、 3357.53 、 171.38$ 和 $118.85 \mathrm{t}$.

浮游动物 $\mathrm{P} / \mathrm{B}$ 系数以 50 计; 鱼类对浮游动物的利用率 $a$ 以 0.3 计; 鱼类对浮游动物的转化率 $K$ 以 0.1 计; 根据浮游动物渔产潜力公式, 得出各湖区渔产潜力分别为 13286. 70、41197.78、4198.23 和 $1245.60 \mathrm{t}$. 根据底栖动物渔产潜力计算公式, 各湖区渔产潜力分别为 $2521.5 、 7020.9 、 661.6$ 和 $1340.8 \mathrm{t}$.

\section{表 1 太湖水生生物资源量}

Tab. 1 Biomass of aquatic organisms in Lake Taihu

\begin{tabular}{lrccc}
\hline \multicolumn{1}{c}{ 资源量 } & 北湖区 & 大湖区 & 东部沿岸区 & 东太湖 \\
\hline 浮游植物 $/(\mathrm{mg} / \mathrm{L})$ & 6.02 & 3.70 & 1.49 & 2.29 \\
浮游动物 $/(\mathrm{mg} / \mathrm{L})$ & 12.95 & 9.09 & 7.31 & 4.81 \\
底栖动物 $/(\mathrm{mg} / \mathrm{L})$ & 165.6 & 123.4 & 91.8 & 236.9 \\
水生植物总生物量 $/ \mathrm{t}$ & \multicolumn{5}{c}{$128.3 \times 10^{4}$} & & \\
\hline
\end{tabular}

水生植物年最大生物量出现在秋 季, 2007 年太湖秋季水生植物总生物量 为 $128.3 \times 10^{4} \mathrm{t}($ 表 1$)$. 设计太湖允许鱼 类对水草的最大利用率为 $20 \%$,水草的 饵料系数一般取 $120^{[6]}$, 推算太湖草食性 鱼类生产潜力为 $2138 \mathrm{t}$.

由此可以初步推断, 太湖仅浮游生 物、水生植被和底栖动物资源潜力约为 $78494 \mathrm{t}$, 其中还不包括水域的细菌和有

机碎屑等重要饵料转换的渔产潜力. 可见, 理论上渔产潜力要更高.

\section{3 太湖鱼类人工放流合理措施}

2006 年太湖鱼类捕捞产量为 $30971 \mathrm{t}$, 已达估算的全湖总渔产潜力的 40\% 左右. 实施保护水环境的可持 续发展渔业, 太湖渔产潜力以总和的 $80 \%$ 为宜, 由此渔产潜力可再增加 1 倍, 增产 $30000 \mathrm{t}$ 左右, 而这一潜力 主要体现在对氮磷转化的渔业潜能上. 太湖自 1964 年起, 开始有组织地进行鱼类人工放流工作, 太湖人工 放流的主要鱼类是鲢、鳙、草鱼、青鱼、鲂及鲤, 放流量以鲢鳙和鲤夏花为主. 从历年放流量、捕捞量、放流规 格和 2007 年测算的肥满度等几个方面分析, 研究提出合理的鱼类放流措施.

2.3.1 鲢、鳙鱼人工放流的措施与依据 鲢鳙作为太湖主要的放流对象, 放流是一直连续的, 且在大多数年 份鲢鳙产量与放流量变化一致(图 1a), 说明人工放流的效果较明显. 但是产量与放流量并不呈显著正相关 (图 2), 可见, 捕捞产量不仅仅依赖于放流量, 还与放养鱼种存活率、放养规格、湖泊生态因子等有关 ${ }^{[7]}$.

综合分析 1993-2006 年太湖鱼类放流资料, 鲢鳙总放流量为 $7082.63 \times 10^{4}$ 尾, 总捕捞量约 $13702 \mathrm{t}$, 鲢、 鳙捕获的平均规格为 $850 、 1260 \mathrm{~g} /$ 尾, 平均回捕率为 $23.9 \%$; 2001 年以后鲢鳙鱼种放流量标准为鲢 $150 \times$ $10^{4}$ 尾 $/ \mathrm{a}$, 鳙 $500 \times 10^{4}$ 尾 $/ \mathrm{a}$; 推算目前鳙、鲢年产量约达 $1500 、 300$ t. 根据 2007 年太湖渔业资源调查, 鲢肥满 度 1.76 , 鳙肥满度 1.88 , 两者均处于优等状态, 所以可以适度增加鲢鳙放流量. 若要达到太湖目前浮游植物 渔产潜力的 $80 \%$, 鲢鲔放流数量可再增加 1 倍, 即放流鲜约 $1000 \times 10^{4}$ 尾, 鲢约 $300 \times 10^{4}$ 尾, 放流形式以冬片 鱼种放流, 鱼种规格仍以目前的 20 尾 $/ \mathrm{kg}$ 为宜.

2.3 .2 草鱼、团头鲂人工放流的措施与依据 从 1993-2006 年草鱼放捕统计资料来看 (图 1b), 草鱼放流量 与产量之间相关性不明显, 1997 年以前草鱼放流量与产量甚至呈负相关, 这可能与放流量不足以及放流规 格偏小有关. 1993-1997 年均放流量 $49 \times 10^{4}$ 尾, 年产量 $317.8 \mathrm{t}$, 放流规格约为 61 尾 $/ \mathrm{kg} ; 1997$ 年后, 年均放 流量 $173 \times 10^{4}$ 尾, 年产量 $447.5 \mathrm{t}$, 放流规格约为 44 尾 $/ \mathrm{kg}$, 随着 1997 年后草鱼放流量和放流规格的增加, 草 鱼产量也呈现上升的趋势. 团头鲂在太湖作为定居型鱼类, 目前采取繁殖保护为主, 人工放流为辅的方针, 产量一直保持在较稳定的水平, 放流量与产量间的相关性也不大 (图 1c).

1993-2006 年放流资料表明, 草鱼人工放流规格约为 50 尾 $/ \mathrm{kg}$, 草鱼年均放流量 $125 \times 10^{4}$ 尾, 年产量 $383.5 \mathrm{t}$, 回捕率为 $23.5 \%$; 团头鲂人工放流规格约为 50 尾 $/ \mathrm{kg}$, 年均放流 $137 \times 10^{4}$ 尾, 年产量 $198.7 \mathrm{t}$, 回捕率约 
$11 \%$. 草食性鱼类草鱼和团头鲂主要生活在水草繁茂的东部湖区,长势良好,2007 年夏季测定时,草鱼的肥满 度 $K=1.51 \sim 1.63$, 团头鲂 $K=2.23$; 太湖富营养化时期,在保护水生植被前提下,发挥其潜力 $50 \%$ 为宜. 综合 太湖历年草鱼、团头鲂的放捕情况, 结合 2007 年太湖水生植被的供饵能力, 建议每年放流草鱼鱼种 $150 \times 10^{4}$ 尾,放流规格 30 尾 $/ \mathrm{kg}$; 每年放流团头鲂鱼种 $165 \times 10^{4}$ 尾,规格提高至 30 尾 $/ \mathrm{kg}$; 放流形式均以冬片鱼种放流 为主.

2.3 .3 青鱼、鲤的人工放流依据 青鱼、鲤是底层鱼类, 青鱼主食黄蚬、螺等; 鲤属杂食性鱼类, 偏向动物食 性,成鱼主食螺、蚌、蚬,其次为底栖寡毛类、水生昆虫和介形类 ${ }^{[8-9]}$. 就栖息水层和食性而言, 青鱼与鲤存在 食物竞争关系, 两者如果在太湖大量繁殖, 必将导致螺蚌资源的迅速衰退. 太湖螺蚌资源因过度捕捞已出现 衰退现象, 主要湖区的螺贝生物量由 1988 年的 $77.12 \times 10^{4} \mathrm{~g} / \mathrm{hm}^{2}$ 降至 2003 年的 $65.36 \times 10^{4} \mathrm{~g} / \mathrm{hm}^{2[10]}, 2007$ 年则下降至 $40 \times 10^{4} \mathrm{~g} / \mathrm{hm}^{2}$, 因此, 青鱼、鲤的放养必须以保护螺蚌资源为前提.

青鱼在太湖不能自然繁殖, 全部依赖于人工放流,太湖青鱼放流为间歇性的, 1993-2006 年之中, 只有 6 年实行放流,共计 $574 \times 10^{4}$ 尾; 放流规格约为 43 尾 $/ \mathrm{kg} ; 1996-2005$ 年青鱼年捕捞量维持在较低的水平,在 $38 \sim 115 \mathrm{t}$ 之间,2006 年达到最高值 $330 \mathrm{t}$ (图 1d). 太湖放流的青鱼生长快, 1 龄鱼平均体重达 $450 \sim 490 \mathrm{~g} ; 2$ 龄达 $1000 \sim 1200 \mathrm{~g}$; 3 龄达 $2800 \sim 3500 \mathrm{~g}$. 要合理控制青鱼的放流,每年放流青鱼 $8 \times 10^{4} \sim 10 \times 10^{4}$ 尾, 规格 以 $20 \sim 30$ 尾/ $\mathrm{kg}$ 为宜, 年产量 $80 \sim 100 \mathrm{t}$ 较为适中,放流形式仍采用冬片鱼种形式. 太湖自 1996 年开始每年 开展鲤夏花投放,1996-2006 年 11 年内,太湖鲤夏花投放累计 $25205 \times 10^{4}$ 尾,年均投放 $2521 \times 10^{4}$ 尾. 自 1998 年以来,太湖鲤渔获量基本浮动在 $1000 \sim 1400 \mathrm{t}$ 左右,产量相对稳定 (图 1e ). 为维护太湖渔业的良性循环,认 为鲤的产量不宜大幅增长, 以每年放流鲤夏花 $2500 \times 10^{4}$ 尾, 使其捕捞产量保持在每年 $1200 \sim 1400 \mathrm{t}$ 为宜.

2.3 .4 渔业资源小型化的调控与尧嘴鲌人工放流的依据 小型低值鱼梅鲛在产量上占优势与其丰富的饵料 基础有关. 2007 年太湖浮游动物的渔产潜力占总渔产潜力的 $76 \%$,梅鲚正是以浮游动物为主食, 丰富的饵料 基础成为它繁衍的保证. 趐嘴鲌是敞水性中上层肉食性鱼类, 以捕食梅魰为主, 是太湖梅魰的首要 “克星”. 要控制梅鲚的产量,抑制太湖渔业“小型化”、“低龄化”、“低值化”特征,强化尧哪嘴鲌的繁殖保护与人工放流 是必要的. 按生态学物质能量传递“十分之一”定律推算 ${ }^{[11]}$, 增长 $1 \mathrm{~kg}$ 鲌鱼, 可以抑制 $10 \mathrm{~kg}$ 梅鲚的增长; 多 生产 $100 \mathrm{t}$ 翅嘴鲌,大约可使梅鲚产量下降 $800 \sim 1000 \mathrm{t}$. 近年梅鲚年产量一直维持在 $21000 \mathrm{t}$ 以上, 如果翘嘴 鲌产量由目前的 $280 \mathrm{t}$ 上升至 $900 \mathrm{t}$, 按理论推算, 可使梅鲚产量降至 $15000 \mathrm{t}$; 此时梅鲚与鲌产量比值为 16: 1 , 从渔产品整体质量和经济效益来看, 是相对合理的.

太湖鲌产量 1993-1995 年由高峰值 $922 \mathrm{t}$ 跌至 $128 \mathrm{t}$, 此后产量维持在 100 200 t 之间,2006 年增产至 $289 \mathrm{t}$ (图 1f). 鲌资源的锐减与 1990s 起高强度的捕捞和酷捕性渔具频繁使用,以及在产卵季节对亲鱼的针对 性捕杀和产卵繁殖场所受到破坏有关 ${ }^{[12]}$. 太湖鲌鱼的增殖措施除了控制捕捞强度、保护鲌鱼繁殖群体和产卵 场之外,采取人工放流措施促使其资源增值也是很好的方法. 太湖自 2002 年开始进行翘嘴鲌的鱼苗和夏花 鱼种人工放流,其增殖效果相当显著; 2002-2004 年连续三年放流鲌鱼苗或夏花鱼,使其产量维持在 $130 \sim 160$ t左右,2005 年鲌鱼没有放流,当年产量下降了 1/3, 仅为 $91 \mathrm{t}$;2006 年投放鲌鱼、夏花鱼种 $170 \times 10^{4}$ 尾, 年内鲌鱼产量达 $289 \mathrm{t}$, 为近年来的最高值. 2002-2004 年均放流量约 $85 \times 10^{4}$ 尾,年均产量 $150 \mathrm{t}$. 因此要 达到控制梅魰产量, 使得鲌产量维持在 $900 \mathrm{t}$ 左右, 鲌鱼种的放流量预计要达到 $500 \times 10^{4}$ 尾左右, 且从人工 放流的效果来看, 以投放夏花鱼种较好.

\section{3 讨论}

\section{1 合理人工放流对优化太湖渔业结构的作用}

根据太湖 2007 年渔业资源调查和渔业历史资料可以看出 ,太湖鱼类品种单一化和鱼类资源“小型化、 低龄化、低值化” 表现明显. 因此,太湖渔业资源调控关系到渔业生产方式调控, 渔业生产方式调控主要涉及 鱼类放流结构调整,包括鱼类放流数量和种群结构的调整,这是稳定太湖渔业产量的重要措施. 太湖曾有记 录 107 种鱼,2007 年调查太湖鱼类已不足 60 种,表明太湖原有鱼类的生态位大量空缺, 从而为放流鱼类提 供了良好的生态条件. 根据水域饵料资源确定鱼类放养量, 是湖泊渔业中鱼类组成管理的主要调控依据 ${ }^{[13]}$, 太湖丰富的饵料生物资源为放流鱼类生长提供了良好的摄食条件,太湖鱼种放流应以太湖生物饵料渔产潜 

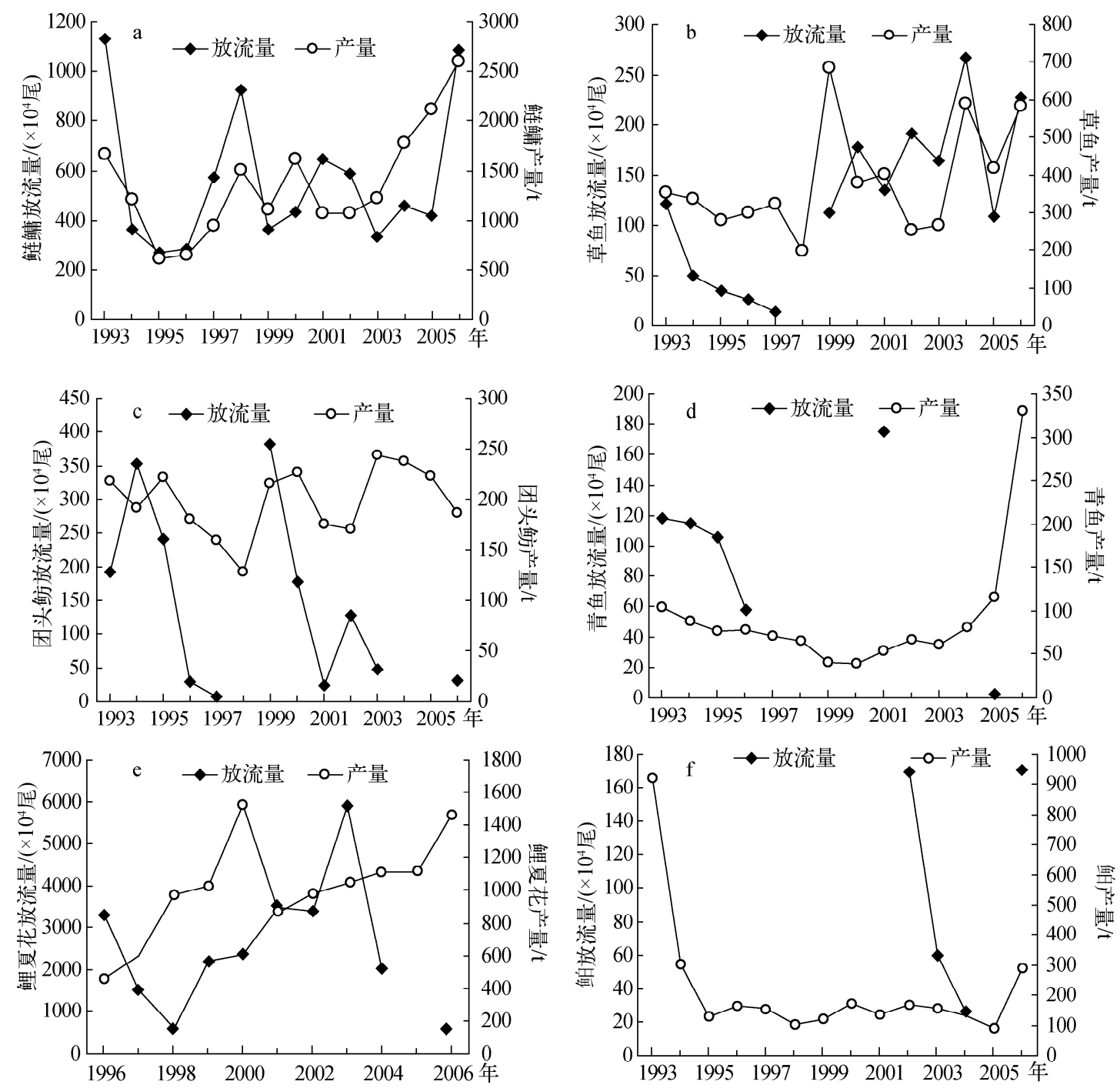

图 1 鲢鳙 $(a)$ 、草鱼 $(b)$ 、团头鲂 $(c)$ 、青鱼 $(d)$ 、鲤夏花 $(e)$ 和鲌 $(f)$ 的种放流量与产量变化

Fig. 1 The changes of stocking numbers and yields of silver carp and bighead carp(a), grass carp (b), blunt snout bream(c), black carp(d), common carp(e) and topmouth cutler(f)

力为依据合理放流. 太湖鱼种放流要坚持原有鱼类区系作为放流对象, 放流种类以“四大家鱼”为主,并补充 在太湖能自然繁殖的鲤、团头鲂等常规鱼类. 同时还要兼顾肉食性鱼类如翘嘴鲌的放流, 利用食物链关系转 化低值鱼类梅鲚, 延长食物链, 提高太湖渔业附加值. 其次, 要坚持放流大规格鱼种, 放流规格越大, 鱼类生 长速率越快, 成活率和回捕率也越高 ${ }^{[14-15]}$; 放流的同种鱼规格不宜相差太悬殊, 否则在太湖捕捞强度未得到 控制的情况下,过小的鱼种在当年会成为价值低的“小杂鱼”而被捕出.

\section{2 合理人工放流对改善太湖水环境的作用}

从太湖环境角度看, 太湖水体富营养化进程逐年加快. 目前, 太湖约 $3 / 4$ 水域达富营养水平;平均每 $10 \mathrm{a}$ 左右水质下降一个级别, 2000 年后下降速度明显加快; 自 1980s 起, 以微囊藻为优势种的蓝藻水华在太湖东 部和北部湖区如梅梁湾、竺山湾、贡湖湾水域频繁暴发, 覆盖面积逐步扩大, 严重影响周边地区工业和生活 用水 ${ }^{[10]}$. 鱼类作为湖泊生态系统中较高级的消费者, 通过上行效应和下行效应与环境间存在着紧密的相互 
作用关系 ${ }^{[16-19]}$. 如何利用渔业手段, 通过鱼类的活动和生长, 对富营养化物质进行利用并转化输出, 这是太 湖水环境改善和生态修复的重要内容和关键所在,也是我国湖泊渔业必须重视的问题 ${ }^{[20-21]}$.

在研究鱼类改善水环境过程中,利用鲢鯆控制 蓝藻的“非经典操纵”理论和在武汉东湖的成功实 践受到国内外的广泛关注 ${ }^{[22]} .2004$ 年和 2005 年在 太湖梅梁湾 $1.4 \mathrm{~km}^{2}$ 围栏水域内进行的鲢鯆控藻实 验表明,每生产 $1 \mathrm{t}$ 鲢鳙鱼, 可以消除蓝藻 $11.4 \mathrm{t}$ 以 上 $^{[23]}$. 因此, 在太湖通过扩大鲢鲜的放流量以减轻 蓝藻水华的危害, 不失为一种较好的生态调控措 施. 水生植物作为生态系统的重要组成, 一方面, 为 其他生物如浮游动物、底栖动物等提供栖息、繁殖 和庇护的场所 ${ }^{[24-25]}$; 另一方面, 还可以有效地吸收 湖泊中的营养盐物质, 以及吸收、降解人工合成物 质和有害物质, 因此, 常常作为水质净化的手段之 ${ }^{[26]} .2007$ 年太湖水生植物遥感调查表明,太湖目 前水生植物资源大面积减少. 因此, 草食性鱼类放 流要在保护水生植物资源前提下进行,并且放流地

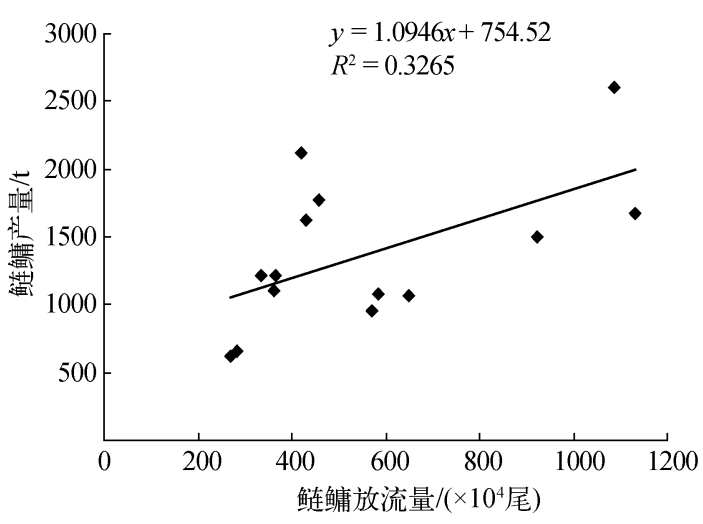

图 2 鲢鲔产量与鱼种放流量关系

Fig. 2 Relationship between the yield and stocking number of silver carp and bighead carp 点要选择水生植物资源丰富的水域,如东部各湖湾

等. 鲤、青鱼的主要摄食对象软体动物具有水质净化功能 ${ }^{[27-28]}$; 同时, 鲤、青鱼寻受食物时摚动沉积物, 使之 回复悬浮状态或在消化活动中释放氮磷, 从而导致水体氮磷含量增加 ${ }^{[29]}$. 因此要以保护太湖水环境和底栖 动物生物多样性为前提, 适当放流. 我国湖泊的渔业生产方式长期以来是以提高鱼类产量为目的, 以充分利 用饵料生物资源和提高覀料能量转化效率为依据, 因此肉食性凶猛鱼类通常作为控制的对象加以清除 ${ }^{[30]}$. 但是, 国外的研究表明, 利用湖泊顶级消费者—凶猛性鱼类, 来调控浮游动物食性鱼类种群数量, 使之通 过营养级联动效应, 可以达到调控湖泊生态系统的目的 ${ }^{[31]}$; 这一方法, 在北美和北欧国家的湖泊管理应用中 研究比较深人 ${ }^{[32-33]}$; 但是这一理论目前仍存在较多争议,并且成功的生物操纵存在一定的环境条件限 制 ${ }^{[34-35]}$. 在太湖, 梅鲚是摄食浮游动物的主要鱼类之一, 能否通过增殖㲐䎊嘴鲌的数量控制梅魰产量, 从而抑 制藻类繁殖值得进一步探讨.

\section{4 结论}

1) 根据 2007 年太湖生物资源调查, 推算出太湖浮游植物、浮游动物、底栖动物和水生植物总渔产潜力 为 $78494 \mathrm{t}$, 而理论上的渔产潜力会更高. 要实施保护水环境的可持续发展渔业, 太湖渔产潜力应以总和的 $80 \%$ 为宜, 目前的渔产潜力可再增加 1 倍, 增产 $30000 \mathrm{t}$ 左右.

2) 根据太湖渔业生产潜力,结合太湖历年鱼类放流量、捕捞量、放流规格和 2007 年测算的肥满度等资 料,综合分析了太湖主要放流鱼类鲢、鳙、草鱼、鲂、青鱼、鲤及肉食性鱼类尧嘴鲌合适的放流量和放流规格. 认为应加大鲢、鳙放流数量, 推算每年放流鳙约 $1000 \times 10^{4}$ 尾, 鲢约 $300 \times 10^{4}$ 尾, 规格为 20 尾 $/ \mathrm{kg}$ 为宜, 在提 高鱼产量同时对抑制太湖蓝藻水华起到积极作用. 草鱼、团头鲂、鲤要在保护太湖水草和底栖动物资源和生 物多样性前提下适当放流,每年宜放流草鱼 $150 \times 10^{4}$ 尾, 团头鲂 $165 \times 10^{4}$ 尾, 青鱼 $8 \times 10^{4} \sim 10 \times 10^{4}$ 尾,鲤夏 花 $2500 \times 10^{4}$ 尾. 而对调控鱼类结构小型化和提高湖渔业附加值具有重要作用的肉食性鱼类尧嘴鲌应加大 放流量,年放流量可扩大至 $500 \times 10^{4}$ 尾左右, 同时要加强繁殖保护.

\section{5 参考文献}

[1 ] 王苏民, 窦鸿身. 中国湖泊志. 北京: 科学出版社, 1998:16-17,22-23,80-113.

[2] 何 俊, 谷孝鸿, 白秀玲. 太湖渔业产量结构及其对水环境的影响. 海洋湖沼通报, 2009, (2) :143-150.

[ 3 ] 王 瀷, 梁彦龄. 用浮游植物生产量估算武昌东湖鲢、鳙生产潜力与鱼种放养量的探讨. 水产学报, 1981, 5(4): 
343-350

[4] 王 骥. 水体生物生产力. 见: 刘建康编. 东湖生态学研究 (一). 北京: 科学出版社, 1990: 167-201.

[5] 梁彦龄, 吴天惠, 谢志才. 保安湖底栖动物现状及渔业评价. 见: 梁彦龄编. 草型湖泊资源、环境与渔业生态学 管理 (一). 北京: 科学出版社, 1995: 178-193.

[6]陈洪达, 何楚华. 武昌东湖水生维管束植物生物量及其在渔业上的合理利用问题. 水生生物学集刊, 1975, 5: 410-419.

[ 7 ] 陆伟民, 童合一. 太湖人工放流鲢、鳙效果的研究. 上海水产大学学报, 1994, 3(3): 112-120.

[ 8 ] Hussen SA, AI-Daham NK, AI-Kanaani SM. Selection of benthic mollusks and macrocrustaceans and their importance in the diet of three sympatric fish species in Garma marshes Iraq. Mar Mesopotamia, 1991, 6(2) :263-280.

[9] 倪 勇, 朱成德. 太湖鱼类志. 上海: 上海科学技术出版社, 2005:44-48.

[10] 秦伯强, 胡维平, 陈伟民等. 太湖水环境演化过程与机理. 北京: 科学出版社, 2004: 19, 280.

[11] 孙儒泳, 李 博, 诸葛阳等. 普通生态学. 北京: 高等教育出版社, 1993.

[12] 刘恩生, 吴林坤, 曹 萍等. 太湖鲌鱼数量变化规律及生态效应分析. 水利渔业, 2007, 27(3): 70-73.

[13] 陈洪达. 湖泊水库渔业的合理放养. 淡水渔业, 1981, (4) :5-10.

[14］曹富康. 水库放养鱼种规格指标和解决办法. 淡水渔业科技杂志, 1976, (2) : 27-30.

[15] 朱松泉, 刘正文, 谷孝鸿. 太湖鱼类区系变化和渔获物分析. 湖泊科学, 2007, 19(6): 664-669.

[16] Brooks JI, Donson SI. Prediction, body size and the composition of plankton. Science, 1965, 150: 28-35.

[17] Carpenter SR, Kitchell JF, Hodgson JR. Cascading trophic interactions and lake productivity. Bioscience, 1985, 35: 634-639.

[18] McQueen DJ. Manipulating lake community structure: where do we go from here? Freshwater Biology, 1990, 23: 613-620.

[19］黄玉瑶. 内陆水域污染生物学一一原理与应用. 北京: 科学出版社, 2001: 53-154, 248-254.

[20］张国华, 曹文宣, 陈宜瑜等. 湖泊放养渔业对我国湖泊生态系统的影响. 水生生物学报, 1997, 21(3): 271-280.

[21] 刘恩生. 鱼类与水环境间相互关系的研究回顾和设想. 水产学报, 2007, 31(3) : 391-399.

[22] Xie P, Liu J. Practical success of biomanipulation using filter fish to control cyanbacteria blooms: a synthesis of research and application in a subtropical hypereutrophic lake. The Scientific World Journal, 2001, (1) : 337-356.

[23] 秦伯强, 胡维平, 刘正文等. 太湖水源地水质净化的生态工程试验研究. 环境科学学报, 2007, 27 (1): 5-12.

[24] Soszka GJ. Ecological relations between invertebrates and submerged macrophytes in the lake littoral. Ekologia Polska, $1975, \mathbf{2 3}(3)$ : $393-415$.

[25] Perrow MR, Jowitt AJD, Stansfield JH et al. The practical importance of the interactions between fish, zooplankton and macrophytes in shallow lake restoration. Hydrobiologia, 1999, 395/396: 199-210.

[26] Inaba K. Seasonal change of ability of self-purification for synthetic detergents in wetland. Fbid, 1988, 119: 19-30.

[27 ] Gardner WS, Cavaletto JF, Johengen TH et al. Effects of the zebra mussels, Dreissena polymorpha, on community nitrogen dynamics in Saginaw Bay, Lake Huron. Journal of Grest Lakes Research, 1995, 21(4) : 529-544.

[28 ] Bastviken DTE, Craco NF, Cole JJ. Experimental measurements of zebra mussel(Dressena polymorph) impacts on phytoplankton community composition. Freshwater Biology, 1998, 39: 375-386.

[29] Tatrai I, Istvanovics V. The role of fish in the regulation of nutrient cycling in Lake Balaton. Freshwater Biology, 1986, 16 : $417-424$.

[30］刘建康. 东湖渔业增产试验综述. 海洋与湖沼, 1980, 11(2) : 185-188.

[31] Carpenter SR, Kitchell JF, Hodgson JR. Cascading trophic interactions and lake productivity. Bioscience, 1985, 35: 634-639.

[32] Drenner RW, Hambright KD. Biomanipulation of fish assemblages as a lake restoration technique. Archiv fiur Hydrobiologie, 1999, 146: 129-165.

[33] Kasprzak P, Benndorf T, Mehner T et al. Biomanipulation of lake ecosystem: an introduction. Freshwater Biology, 2002, 47: 2277-2281.

[34] Mason DM, Brandt SB. Effect of spatial scale and foraging efficiency on the predictions made by spatially-explicit models of fish growth rate potential. Environmental Biology of Fishes, 1996, 45: 283-298.

[35] Thomas M, Jürgen B, Peter K et al. Biomanipulation of lake ecosystems: successful applications and expanding complexity in the underlying science. Freshwater Biology, 2002, 47: 2453-2465. 